\title{
Displacement Measurements at a Connector Contact Interface Employing a Novel Thick Film Sensor
}

\author{
Yu-Zhi (Liza) Lam, John W. McBride, Christian Maul, and John K. Atkinson
}

\begin{abstract}
One of the key failure mechanisms for wiring and connector systems used in the automotive industry, is fretting and fretting corrosion at the contact interface of connectors. For many years, procedures have been carried out under laboratory controlled conditions to investigate both thermal and vibration fretting effects using environmental chambers and fretting tests. Both optical and visual inspections have also been adopted to observe the movement at the contact interface. However, these methods can be considerably inconvenient and costly. Furthermore, their suitability for field applications is limited. In order to study the fretting degradation at the actual interface for in-situ measurement effectively, a novel position sensor is designed to monitor the relative displacement. Thick film techniques are employed to fabricate miniaturized and cost effective resistive devices. The sensor is assembled into a connector sample by taking the place of the male component. When the interface experiences movement, the relative displacement of the contact point would cause a corresponding linear change of resistance measured across the male and female connection. The sensors are validated by a series of experiments and subsequently used in a field test to establish the relationships between the fretting effects with temperature, humidity and differential pressure, which is associated with temperature variation.
\end{abstract}

Index Terms-Fretting, relative displacement, temperature, thick film sensor, vibration.

\section{INTRODUCTION}

$\mathbf{T}$ HE increasing complexity of automotive electrical systems have brought about the need for more demanding connector specifications such as higher pin density as well as a larger range of power and signal requirements. Electrical connectors are essential for the installation and maintenance of components. Their role enables defective parts to be replaced and provides flexibility within an electrical system. The connectors for automotive applications are often subjected to harsh environmental conditions. Long term exposure to extreme levels and rapid variations of vibration, humidity, and temperature deteriorates the connectors and reduces reliability [1].

One of the main causes for connector failure is fretting. Fretting is micro-oscillatory motion that leads to surface damage by

Manuscript received November 14, 2005; revised May 29, 2007. Current version published September 17, 2008 . This work was supported through the European Commission "Growth" programme, research project AUTOCON: "Investigations into integrated wiring and interconnecting of electrical and electronic components for intelligent systems," GIRD-CT01-00588. This work was recommended for publication by Associate Editor R. Lee upon evaluation of the reviewers comments.

The authors are with the School of Engineering Sciences, University of Southampton, Southampton SO17 1BJ, U.K. (e-mail: 112004@alumni.soton.ac. uk).

Color versions of one or more of the figures in this paper are available online at http://ieeexplore.ieee.org.

Digital Object Identifier 10.1109/TCAPT.2008.2001133 wear. This phenomenon is particularly important on plated surfaces where for example Au can wear through to a substrate material and is particularly important with Sn plated surfaces where fretting corrosion can occur. This phenomenon occurring at the contact interface is due to stresses contributed by vibration and differences in thermal expansion of contact materials [2]. The nature of stresses are divided into two main categories namely external stresses caused by external environment and internal stresses that are generated within the vehicle [3]. Physical parameters such as temperature, pressure and humidity are used to quantify the influences of these stresses. Collectively, they form the fundamental parameters in determining the stability and the contact resistance failure criteria for electrical systems [4].

In view of the environmental influences and the associated fretting behavior, various tests have been used to ascertain reliability [1], [5]. Standardization of these test procedures and parameters has been employed by connector manufacturers to allow uniform assessment [6]. Studies have shown that although these tests have been used as a guide for connector evaluation, in comparison to the results from field experiments [7], the accelerated tests may have unrealistic conditions which induce failure by artificially exceeding the thresholds for a given design. It is also noted that for many measurements, some of the parameters are not obtained from the most likely point of degradation which in most cases is the contact interface. In order to minimize the misrepresentation of the measured results, in-situ measuring techniques should be employed to acquire the various parameters. The in-situ measurement of the environmental parameters was presented in a previous study [8], which forms the basis of the methods presented here. The parameters were measured using commercially available miniaturized sensors which are sufficiently compact to be placed at relatively close proximity to the contact interface.

The objective of this paper is to relate the amount of micromovement at the contact interface with the environmental parameters namely temperature, humidity and differential pressure. In this study, a novel thick film displacement sensor has been developed to monitor the micro-movement at the contact interface. The study involves a series of experiments to cover typical as well as extreme operating ranges by using laboratory equipment to provide the necessary simulations. The investigations are extended to include tests under practical conditions where the same parameters are measured with the connectors placed at various strategic positions around the engine compartment of a vehicle. The procedure is modified from previous field studies for automotive applications where thermal stress levels 


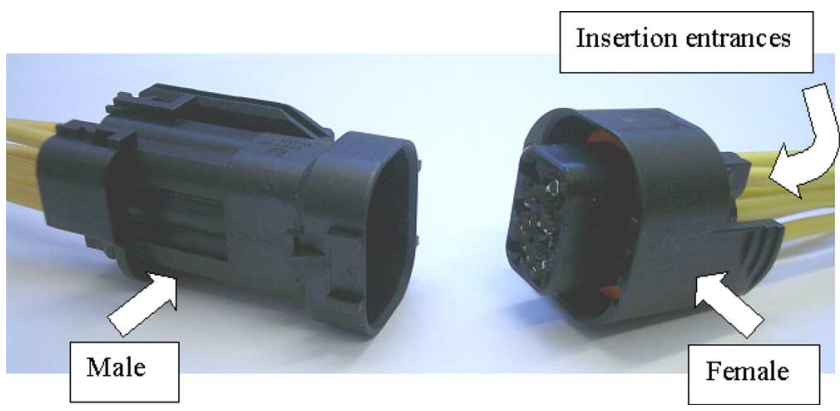

Fig. 1. Connector housing.

inflicted by real world environmental situations have been determined [1], [9].

\section{SEnSOR APPlication To THE CONNECTOR Housing}

\section{A. Connector Housing}

A commercial plastic connector housing as shown in Fig. 1 is used for all the laboratory and field experiments. The housing is made of semi-crystalline, thermoplastic saturated polyester filled with $10 \%$ glass fiber. The interior is designed to include sealing features. The unit accommodates six terminal pairs with multicored cables and at each insertion entrance; a polymer ring is used to seal the individual cable housing cavity. The contact terminals used in the commercial device are Sn plated surfaces.

\section{B. Sensors for Measuring the Environmental Parameters}

The environmental parameters of interest to the investigation are temperature, humidity, and differential air pressure. The sensors used for measuring these parameters are positioned in similar ways as previous study [8]. To measure the on-going changes in temperature near the contact interface, a miniaturized $\mathrm{K}$ type thermocouple measuring approximately $0.5 \mathrm{~mm}$ by $0.5 \mathrm{~mm}$ is sufficiently small to be inserted into the connector housing, as shown in Fig. 2. The insertion entrance of the cable housing cavity enclosing the thermocouple is covered with epoxy so as to retain the sealing capability of the original cables. The voltage output of the thermocouple is connected to a monolithic thermocouple amplifier with cold junction compensation to perform signal conditioning and linearization prior to data acquisition. The relative humidity (\%RH) levels near the contact interface have been measured by a solid-state capacitive-based humidity/moisture sensor with the package dimensions of $9 \mathrm{~mm}$ by $5 \mathrm{~mm}$ (refer to Fig. 2). As the output of the humidity sensor in terms of voltage is linearly proportional to $\%$ RH level, mathematical conversion can be easily performed to obtain the corresponding results.

Increasing interest in the influence of differential pressure arises due to the introduction of well-sealed connector designs. Although this feature allows connectors to be used in a larger range of applications, the concerns about pressure buildup within the connector housing on fretting should be addressed. A change of temperature and therefore air pressure inside the connector housing could lead to micro-movement at the contact interface. This in turn would affect the reliability of the connector. Differential pressure is calculated by taking the difference between the absolute pressures with reference to

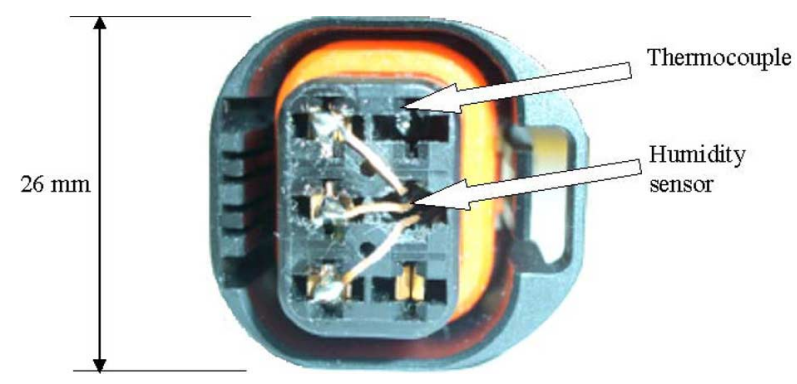

Fig. 2. Position of miniaturized thermocouple within the connector housing.

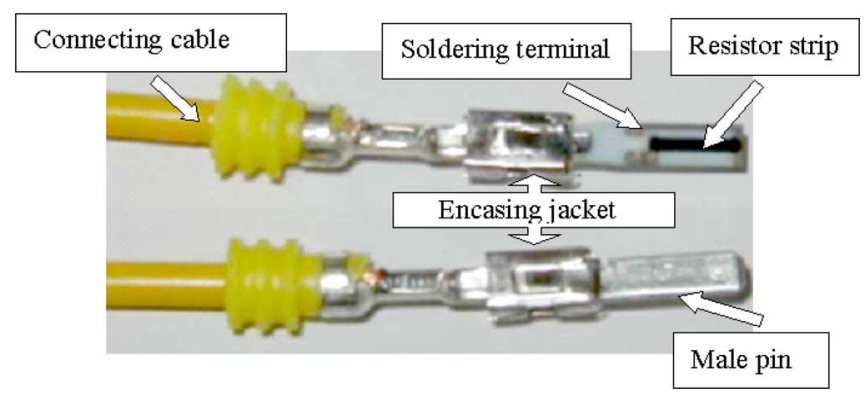

Fig. 3. Thick film position sensor prototype assembled as an equivalent male plug.

vacuum measured inside and outside the connector housing. A piezoresistive pressure sensor is securely attached at the insertion entrance of the cable housing cavity via a protruding port and a second identical sensor is placed outside the housing to measure the external pressure.

\section{Thick Film Sensor for Measuring Micro-Movement}

The physical behavior at the contact points is monitored via a novel sensor design for in-situ measurement. There are mainly two specifications which the sensor needs to satisfy. They include the ability to measure real-time relative displacement at the contact point and the sensor needs to be small enough to be placed inside the connector housing as an equivalent plugsocket assembly without introducing changes to the actual behavior and motion at the contact interface. The use of thick film technology has been exploited to meet the requirement of miniaturization in sensor design [10]. The concept of the sensor design is based on the working principle of a simple voltage divider along a resistive load. The design includes a cermet (glass/PtAg alloy) resistor strip printed along the length of the substrate and soldering terminals are included for external circuitry connection. The $(16 \times 2.8 \times 0.76) \mathrm{mm}$ substrate is chosen to closely match the male terminal so that a direct replacement can be made at the plug assembly as seen in Fig. 3. With a fixed dc voltage applied across the $0.6 \mathrm{~mm}$ wide resistor, the voltage measured by the female terminal corresponds to the position of the contact point as illustrated in Fig. 4. As the contact parts undergo a fretting motion, the voltage measured at the female pin changes accordingly.

A static calibration test has been carried out to quantify the relationship between the measured voltage and the relative displacement. The sliding plate is moved at known intervals of displacements and the corresponding voltage outputs from the fe- 


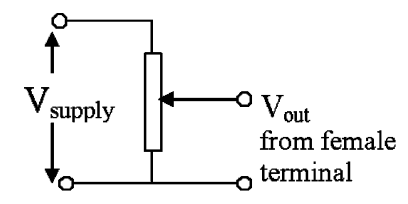

Fig. 4. Schematic representation of sensor's working principle.

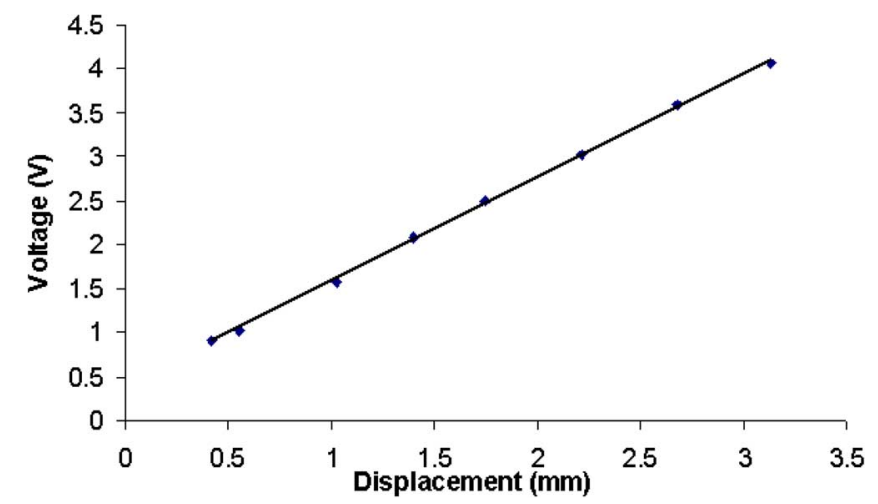

Fig. 5. Static calibration curve of thick film displacement sensor.

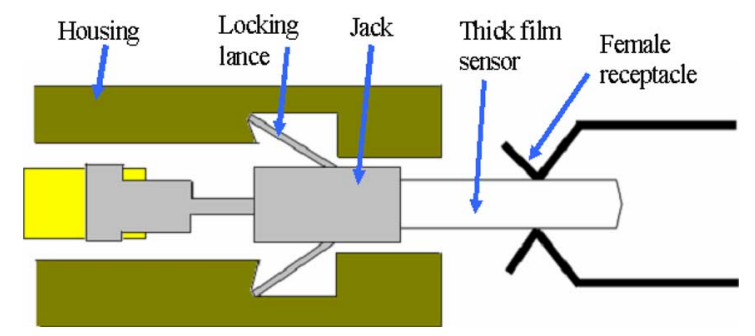

Fig. 6. Cross-sectional view of position sensor assembled in connector housing.

male terminal recorded as shown in Fig. 5. The sensitivity of the sensor was found to be approximately $1.18 \mathrm{~V} / \mathrm{mm}$ with a dc voltage supply $\left(V_{\text {supply }}\right)$ of $5 \mathrm{~V}$. The sensor has been temperature compensated by using another identical device as reference during measurements. With the sensor calibrated, the thick film position sensor is anchored into place by the locking lance of the encasing jack as illustrated in Fig. 6.

\section{Sensor Analysis}

The fabrication process leads to non-ideal characteristics of the thick film position sensor. To determine the contribution of the imbalance in resistance distribution caused by the use of different materials, a simplified analysis can be undertaken and

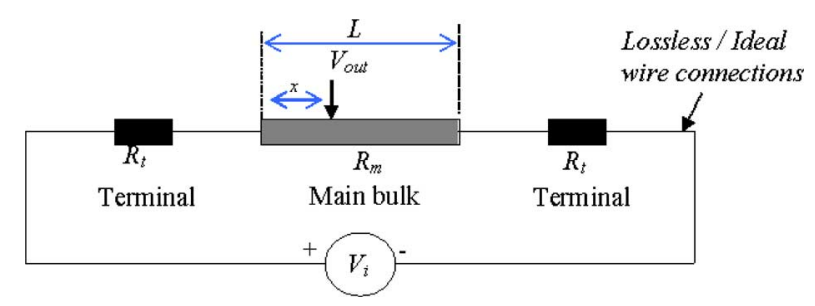

Fig. 7. Electrical equivalent of the thick film sensor.

an electrical equivalent of the sensor as shown in Fig. 7 is employed. The parameter $x$ represents the distance to the contact point and $L$ is the total physical length of the resistor strip. In practice, the resistances $R_{m}$ and $R_{t}$ are variables that are dependent on temperature $T$. The change of output voltage with respect to temperature can be evaluated as (1), shown at the bottom of the page, where $R_{m 0}$ and $R_{t 0}$ are the resistances at $0{ }^{\circ} \mathrm{C} ; \alpha_{m 0}$ and $\alpha_{t 0}$ are the respective temperature coefficients of resistance at $0{ }^{\circ} \mathrm{C}$.

The maximum change of voltage with temperature, $\left(\partial V_{\text {out }} / d T\right)_{\max }$ occurs with (2), shown at the bottom of the page.

Substituting the variables with numerical values gathered from the respective data sheets into (1), the change of output with respect to temperature can be evaluated for different positions of the contact point. This analysis is useful when making choices for the materials required for fabricating the thick film position sensor which in turn, minimizes the influence of temperature on the output due to the imbalance of resistance distribution.

\section{EXPERIMENTAL METHODS}

The experiments are presented in three stages.

Stage 1

Initial tests are conducted to investigate the displacement sensor performance. To simulate the influence of vibration under laboratory conditions, the fretting apparatus shown in Fig. 8 is used [11]. The thick film sensor without the connector housing was subjected to a fretting motion of $100 \mu \mathrm{m}$ at $0.17 \mathrm{~Hz}$. Displacement measurements made are compared to the output from a linear variable displacement transducer (LVDT) at intervals of $1 \mathrm{~s}$. This procedure was repeated for a thick film position sensor assembled into a connector housing. Fig. 9 shows the schematic representation of each configuration and the locations where the sample was clamped and held onto the fretting jig.

$$
\frac{\partial V_{\text {out }}}{\partial T}=V_{i}\left(\frac{1}{2}-\frac{|x|}{L}\right)\left(\frac{\left(\left(2 R_{t 0}+R_{m 0}\right)\left(R_{m 0} \alpha_{m 0}\right)\right)-\left(R_{m 0}\left(2 R_{t 0} \alpha_{t 0}+R_{m 0} \alpha_{m 0}\right)\right)}{\left(\left(2 R_{t 0} R_{m 0}\right)+\left(2 R_{t 0} \alpha_{t 0}+R_{m 0} \alpha_{m 0}\right) T\right)^{2}}\right)
$$

$$
T=\frac{\alpha_{m 0}\left(2 R_{t 0}+R_{m 0}\right)\left(2 R_{t 0}+R_{m 0}\right)\left(2 R_{t 0} \alpha_{t 0}+R_{m 0} \alpha_{m 0}\right)}{\left(2 R_{t 0} \alpha_{t 0}+R_{m 0} \alpha_{m 0}\right)^{2}-\left(\alpha_{m 0}\left(2 R_{t 0}+R_{m 0}\right)\left(2 R_{t 0} \alpha_{t 0}+R_{m 0} \alpha_{m 0}\right)\right)} .
$$




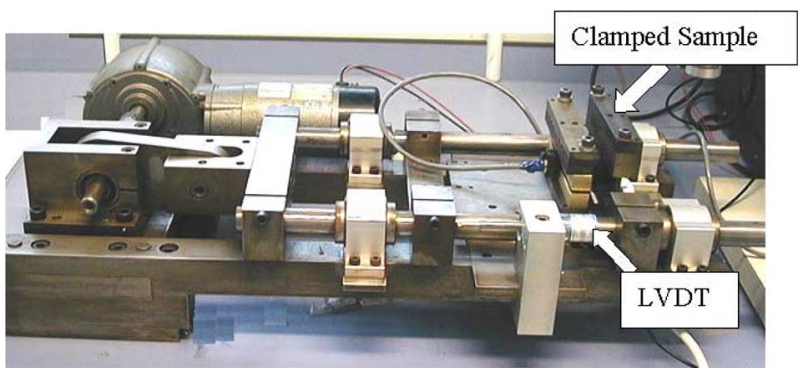

Fig. 8. Fretting jig.

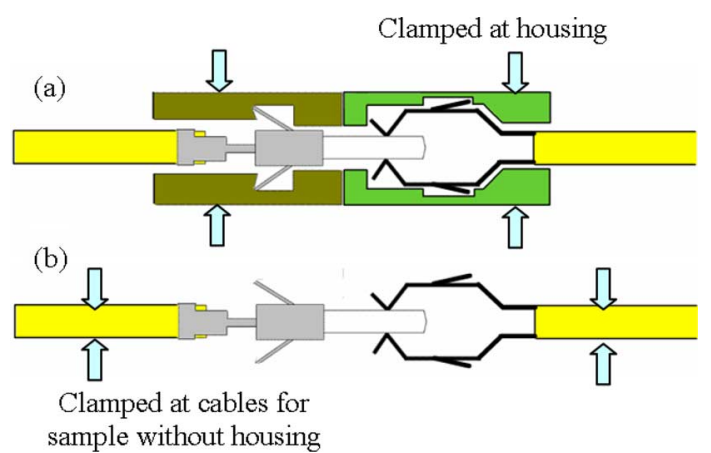

Fig. 9. Clamped positions onto fretting jig for samples (a) with housing and (b) without housing (arrows indicating clamping points).

Stage 2

A series of simulated laboratory experiments were used to evaluate the influences of environmental parameters that result in indirect sources of movement at the contact interface. The connector housings accommodating the thermocouple, humidity sensor, pressure sensors and thick film position sensor were placed in a climatic testing chamber (series SB, System Weiss). In addition, similar sensors were used to record the external parameters. To establish an independent analysis of each environmental factor, a second thick film displacement sensor was positioned in the chamber without the connector housing. The samples were subjected to thermal shock cycles which were modified from the USCAR standards [12] (refer to Fig. 10 for the representation of a single cycle). The complete test consisted of 4 such cycles so that the repeatability of the measurements could be observed.

Stage 3

In this experiment the connector housing is mounted in a test vehicle, and the field test consists of a series of 10-min drive periods on typical UK roads. The connector samples are clamped onto a fixture which is secured within the engine compartment as shown in Fig. 11. The cables were tied to parts of the car frame so that their presence does not interfere with the normal operation of the vehicle. The fitting conditions were carried out accordingly to represent as closely as possible to the situation of a typical automotive connector. Data was acquired from the respective sensors with the same methodology used in the laboratory tests.

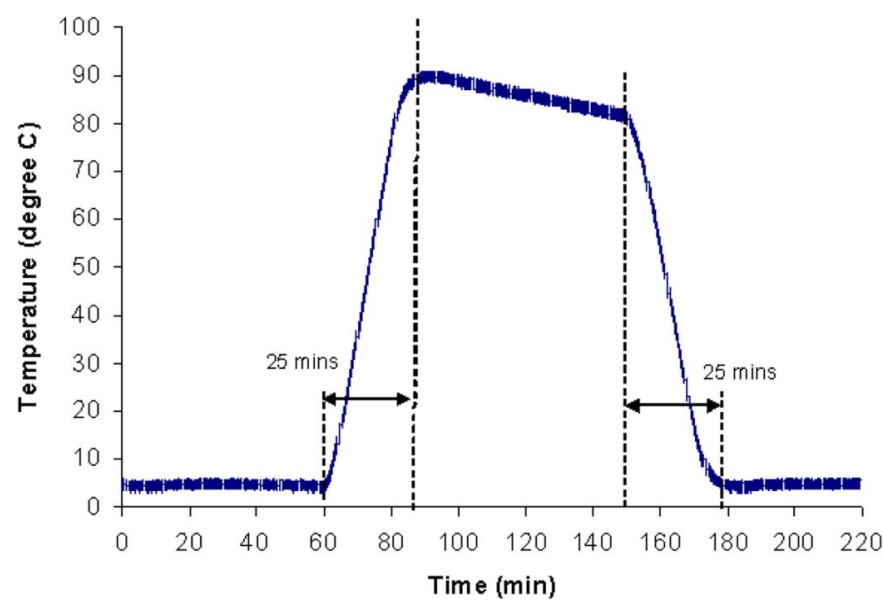

Fig. 10. Single thermal shock cycle.

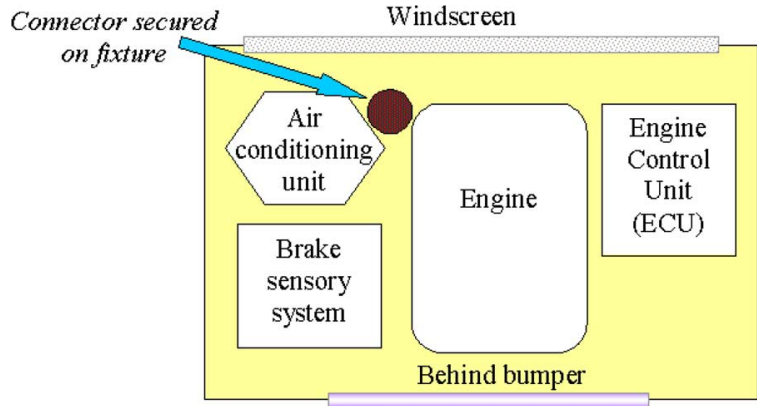

Fig. 11. Connector within engine compartment.

\section{RESUltS AND Discussions}

\section{A. Stage 1 Study: Influence of Forced Fretting}

In this test, 2 sensors were subjected to continuous fretting motion of $100-\mu \mathrm{m}$ amplitude. The sensors with no housing were secured to the fretting jig, held at the connecting cables. The second sensor assembled within the housing was fixed to the fretting jig by clamping the housing structure (see Fig. 9). Fig. 12 shows a comparison of the displacement for the two sensor configurations with the LVDT output. Both sensors show a linear output, with a linear fit shown in the figure. The sample with no housing shows a displacement of approximately $78 \mu \mathrm{m}$, or $78 \%$ of output from the LVDT. This difference can be attributed to misalignment of the thick film sensor, possible 'rocking' motion at the contact point as well as the wire and component flexure.

A key point to be emphasized here is that the influence on the motion characteristics due to the presence of the thick film displacement sensor has been minimized by designing the sensor according to the dimensions of the metallic contact. The thick film surface and the metallic contact surface have also been evaluated to assess the levels of hindrance to movement by subjecting the two contacts to constant tension and compression forces. In this simple experiment, the initial position of the contact point was marked on the thick film surface. After subjecting it to a fixed tension force, the displacement of the contact point was measured. Using the exact same method and setup, the 


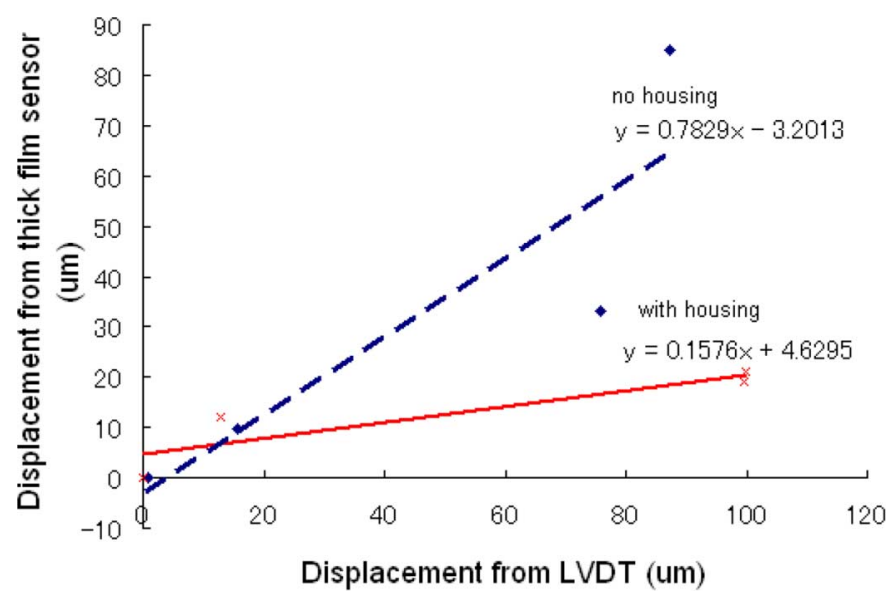

Fig. 12. Displacement measurement made from fretting.

displacement of the contact point for the metallic contact surface was recorded. They were found to be the same, hence suggesting comparable frictional losses. Therefore, the in-situ measurements made are viable representations of the actual changes affecting the contact position.

The sample with the housing clamped onto the fretting jig shows a much reduced displacement of approximately $16 \mu \mathrm{m}$. The difference in results are due to two main features within the housing structure namely the anchorage of the locking lances and the buffered effect created by the rubber-like sealing around the mating area between the male and female components.

\section{B. Stage 2 Study: The Influence of Environmental Parameters}

The results presented are attributed to three main parameters, the differences in thermal expansion of the materials involved, the pressure buildup within the connector housing and the humidity. The influences of the three parameters on micro-movement at the contact point are presented separately. It is important to note that investigations have been carried out using several identical samples and the results presented are typical responses.

1) Temperature: The relationships between the displacement of the contact point and the temperature for the thick film sensor without the housing and the sensor assembled in the connector housing are shown in Figs. 13 and 14 respectively. The temperature range for both the sensors inside and outside the connector housing are from $5{ }^{\circ} \mathrm{C}$ to $90{ }^{\circ} \mathrm{C}$. This agrees with a previous study [8] where the temperature measured inside the connector housing was found to follow relatively closely to the external varying temperature with only a time delay of approximately 5 mins. In Fig. 13, minor movement at the contact interface for the sample without the housing is recorded at an equivalent maximum displacement of $8 \mu \mathrm{m}$. This value is evaluated by taking the difference between the largest and smallest displacement values within the operational temperature range. As temperature increases, the measured displacement at each temperature interval appears to follow an irregular pattern. For the sample assembled in the connector housing (Fig. 14), an overall increase in displacement is observed as temperature increases although between $30^{\circ} \mathrm{C}$ and $60{ }^{\circ} \mathrm{C}$, the output fluctuates. The

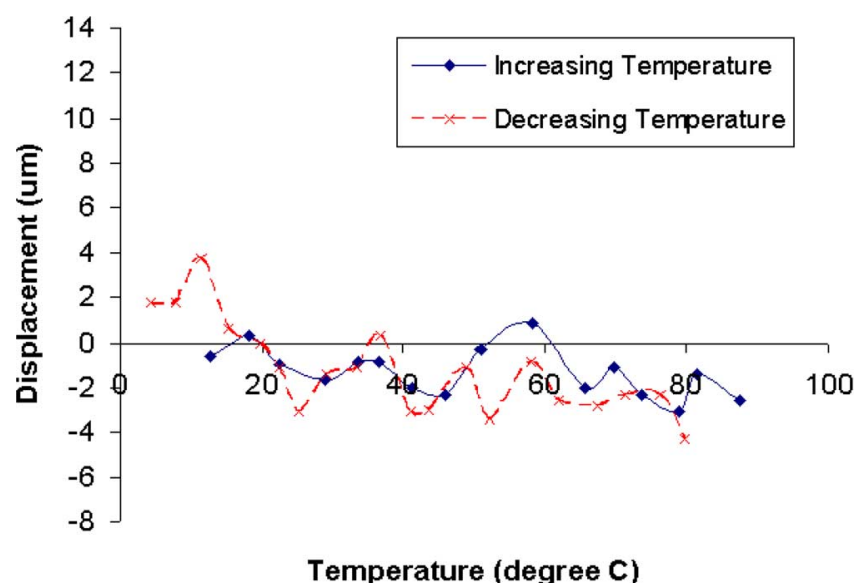

Fig. 13. Relationship between displacement and temperature for sample without housing (no pressure influence).

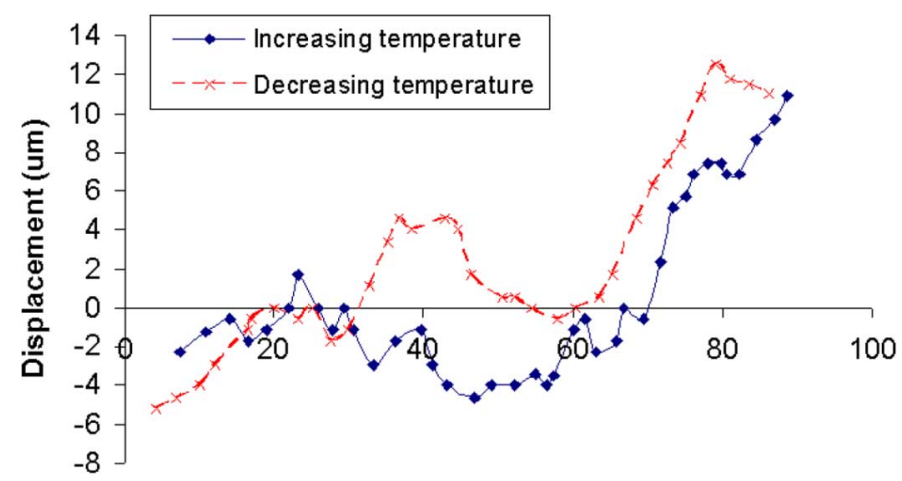

Temperature (degree C)

Fig. 14. Relationship between displacement and temperature for sample assembled in connector housing (with pressure influence).

maximum displacement is in this case $17 \mu \mathrm{m}$ which is approximately three times greater than the sample without housing.

The irregularity of the displacements can be the influences of a number of factors, such as, the temperature resistance relationship, the imbalance in distribution of material resistance along the thick film sensor [13], the presence of electrical noise and the smoothness of contact point movement along the position sensor, also related to the surface roughness.

Consideration of the influence of the temperature change on the materials can be evaluated using the theoretical representation in (1), where the resultant output voltage (or displacement) is inversely proportional to temperature. Using the experimental conditions; $V_{i}=5 \mathrm{~V}, R_{m 0} \approx 10^{5} \Omega, R_{t 0} \approx 10^{3} \Omega, \alpha_{m 0} \approx$ $100 \mathrm{ppm} /{ }^{\circ} \mathrm{C}, \alpha_{t 0} \approx 500 \mathrm{ppm} /{ }^{\circ} \mathrm{C}$ and $(|x| / L) \approx 0.5$ into (1) and (2), the maximum change in output voltage $\left|\left(\partial V_{\text {out }}\right)_{\max }\right|$ is calculated to be in the order of $10^{-9} \mathrm{~V}$ for temperature changing from $90^{\circ} \mathrm{C}$ to $5^{\circ} \mathrm{C}$. The equivalent displacement is in the region of $10^{-6} \mu \mathrm{m}$ which is a significantly small value as compared to conventional fretting amplitudes [14], [15]. It can therefore be concluded that the change of material resistances reflected in the output voltage under thermal influences is negligible. With a low level of electrical noise it is expected that the irregularity in the displacement results from the nature of the motion of the sliding surfaces, which is discussed below. 


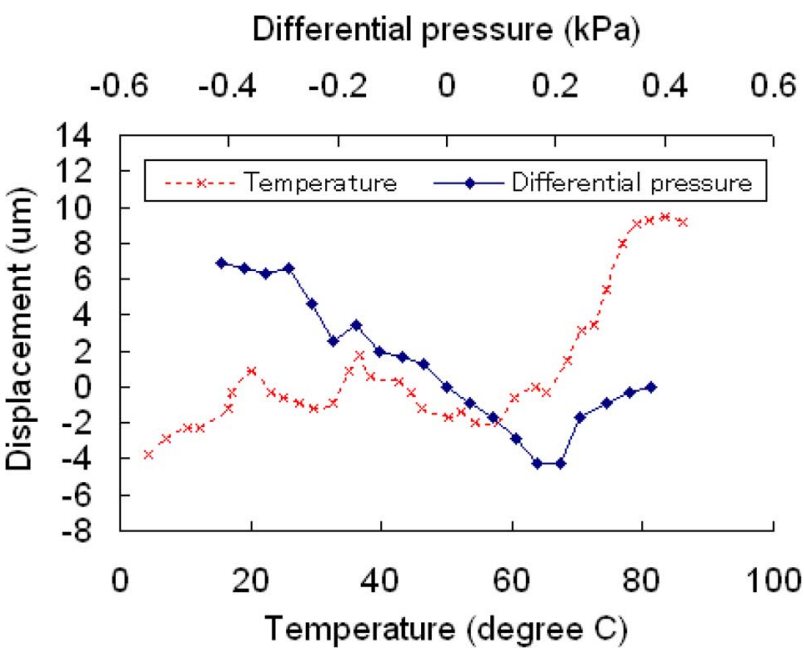

Fig. 15. Relationship between displacement and differential pressure.

2) Differential Pressure: The sealed housing design will lead to a pressure changes as the temperature changes. This creates a difference between the external and internal pressure, allowing components to move. The rise in differential pressure is associated with the temperature cycle as depicted in Fig. 10. Fig. 15 shows the relationship between the displacement measurement and differential pressure as well as temperature (averaged data from Fig. 14). The maximum displacement is approximately $14 \mu \mathrm{m}$.

One of the significant errors is in the nature of the frictional force between the rider and the thick film sensor. This sensor is designed to measure displacement along the sensor main axis. Ideally, if a surface on which the contact moves experiences negligible amount of friction, the relationship between displacement and differential pressure should be linear. However in practice, it is expected that the interface friction, along with the housing to gasket friction and viscoelastic responses of materials would cause non-linear outputs. To examine the interface friction, a 3-D surface profiler (XYRIS 4000CL) has been used to measure the surface profile of the thick film sensor. The surface $(1 \mathrm{~mm} \times 3 \mathrm{~mm})$ shown in Fig. 16, has a wave pattern on the surface which runs perpendicular to the direction of rider motion. This is expected to result in a discontinuous sliding motion with the applied forces. A typical cross-section in Fig. 16(a) shows the roughness along the $1 \mathrm{~mm}$ length of the thick film surface, the averaged surface waviness is $0.8 \mu \mathrm{m}$. The unevenness and non-uniformity may obstruct smooth movement at the contact point and could account for the non-linear response seen in both Figs. 14 and 15.

\section{HUMIDITY}

A previous study [8] has shown that the relative humidity (RH) levels measured inside the connector housing remained unchanged under the condition where the external RH levels was controlled to vary from $30 \% \mathrm{RH}$ to $95 \% \mathrm{RH}$ with temperature kept constant. In order to evaluate the effect of varying RH levels on the sensor output, displacement should be studied with the absence of the connector housing.
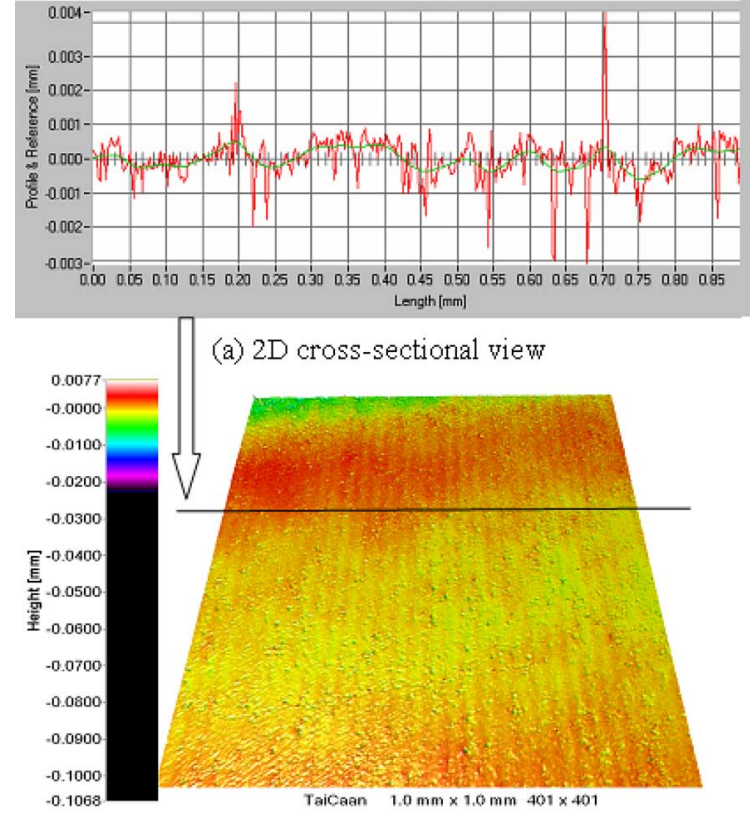

(b) $3 \mathrm{D}$ view

Fig. 16. Surface profile of thick film sensor.

In this experiment, the measured $\mathrm{RH}$ levels inside the connector housing range from approximately $30 \% \mathrm{RH}$ to $50 \% \mathrm{RH}$ throughout the 4 continuous thermal shock cycles. To effectively isolate the influence of $\mathrm{RH}$ levels from temperature variation on displacement, a sample without the connector housing has been subjected to the same range of $\mathrm{RH}$ levels at $25^{\circ} \mathrm{C}$. This result showed that under these conditions movement at the contact interface is not affected by varying RH levels.

\section{A. Stage 3 Study: Field Test With Sensors in the Connector Housing}

The results obtained from a series of field tests were analysed and the relationship between displacement and the environmental parameters of temperature and differential pressure are established as plotted in Fig. 17. It is noted that the temperature measured near the contact point ranges between $27^{\circ} \mathrm{C}$ and $42{ }^{\circ} \mathrm{C}$, giving a temperature change of $15^{\circ} \mathrm{C}$. Under the field test conditions, the differential pressure is found to be between $-0.30 \mathrm{kPa}$ and $0.13 \mathrm{kPa}$. Within this range, the displacement is $14 \mu \mathrm{m}$ and forms a relatively linear relationship to the absolute differential pressure. The increase in temperature is relatively small when compared to the temperature range used in the laboratory test, which in turn reduces the differential pressure change. Using the laboratory results shown in Figs. 14 and 15 , the corresponding calculated displacement for the temperature range of $27{ }^{\circ} \mathrm{C}$ to $42{ }^{\circ} \mathrm{C}$ would be expected to be $7 \mu \mathrm{m}$ and for the differential pressure between -0.30 and $0.13 \mathrm{kPa}$, $12 \mu \mathrm{m}$. The difference between the laboratory differential pressure and field measurement is $2 \mu \mathrm{m}$.

From previous research [1], wear-scars on tin-plated contacts taken from vehicles that had undergone reliability tests involving extreme conditions were found to be as high as a few hundred micrometers. It is anticipated that under normal (less extreme) conditions, the influence of fretting would be reduced 


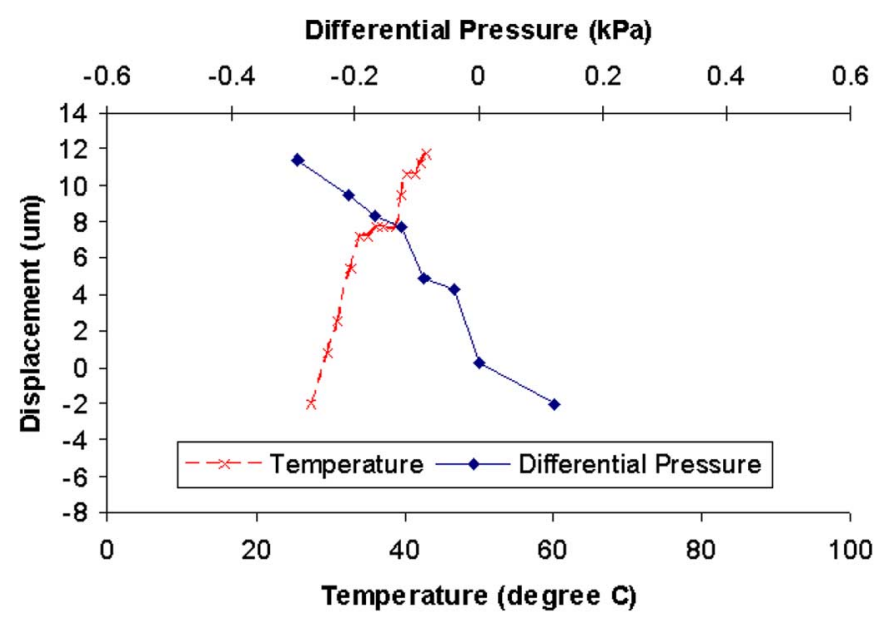

Fig. 17. Influence of environmental parameters on displacement for field test.

accordingly. In the field test the cables or wires connecting the thick film position sensor in the connector housing to the data acquisition system were fixed to different sections of the car frame. This means that when the vehicle is in motion, the vibration experienced at the fixture holding the connector housing would be different from that of the cables. This would result in the flexing of cables due to the influence of forced fretting as described in Section IV-A and this factor would likely be accountable for the difference observed in the outputs. It is also noted that vibration acting on the connector housing used could be up to 6 times larger than the actual movement measured at the contact point (Fig. 12). However, the influence of the vibration was not studied for this investigation.

These field tests have been carried out over a relatively short period of time as compared to the average operational lifespan of a vehicle. Therefore, although the range of parameters may not appear as significant with respect to the laboratory test specifications, the potential of employing the respective sensors for monitoring and evaluating the connector failure mechanisms has been demonstrated.

\section{CONCLUSION}

A novel in-situ position sensor for monitoring fretting motion has been designed and developed using thick film techniques. The sensor allows real displacement measurements to be made at the connector interface in-situ. The results show that after calibration and laboratory testing, the device can be used in a real application, in this case a road tested vehicle.

The thick film displacement sensor, which is a simplified design for limited measurements in only a single lateral axis, proves to be adequate for this initial investigation where the movement of the contact point can be detected. In the event where the movement of the contact point occurs in various spatial directions, a more comprehensive hence complex array of sensing elements would be required. This aspect will be incorporated into the future sensor design so as to achieve a complete account for the displacement

The influence of vibration was studied by applying conventional forced fretting tests in the laboratory. It was found that for a known amount of fretting force (in terms of $\mu \mathrm{m}$ ) exerted on the connector housing, the displacement at the contact point was approximately 0.158 times that of the applied fretting distance, as a result of compliance in the housing.

In the laboratory tests, the influence of pressure as a result of external temperature changes on the sealed connector housing has been shown to be important. The internal pressure changes resulting from the temperature cycling caused micro-movement of approximately $17 \mu \mathrm{m}$ at the contact point.

In the field test study where the samples were placed in the engine compartment of a vehicle which was driven for a number of tests, each lasting approximately $10 \mathrm{~min}$. In general, it was found that the trends depicting relationship between displacement and temperature and differential pressure obtained from the field test agree with that of the laboratory experiments, although the respective absolute magnitudes were different. The field experiment has demonstrated the viability of using the novel thick film sensor for in-situ displacement at the contact interface for practical applications, and that fretting displacement can be measured directly in a real operation environment.

\section{ACKNOWLEDGMENT}

The authors would like to mention Dr. Z. Zhang (previously from University of Southampton, UK) for his valuable contributions towards the thick film displacement sensor, W. Stabroth, Tyco Electronics, Germany, for supplying the connector samples, Dr. F. Huebner-Obenland, Daimler Chrysler, Germany, for the test vehicle, and Dr P. James and T. Hartley, University of Southampton, U.K., for use of the fretting apparatus and for helping with the field test, respectively.

\section{REFERENCES}

[1] J. Swingler, J. McBride, and C. Maul, "Degradation of road tested automotive connectors," IEEE Trans. Compon. Packag. Technol., vol. 23, no. 1, pp. 157-164, Mar. 2000.

[2] S. Hannel, S. Fouvry, P. Kapsa, and L. Vincent, "The fretting sliding transition as a criterion for electrical contact performance," Wear, vol. 249, pp. 761-770, 2001.

[3] J. Swingler and J. McBride, "Fretting corrosion and the reliability of multicontact connector terminals," IEEE Trans. Compon. Packag. Technol., vol. 25, no. 4, pp. 670-676, Dec. 2002.

[4] R. D. Malucci, "Stability and contact resistance failure criteria," in Proc. Joint 22nd Int. Conf. Elect. Contacts 50th IEEE Holm Conf. Elect. Contacts, 2004, pp. 206-213.

[5] C. Maul, J. Swingler, and J. W. McBride, "Monitoring the connector environment in automotive systems," in Proc. IEE Symp. Autom. Electron. Stand., 1999, pp. 5/1-5/4.

[6] Public safety publication, Part 2 tests, Int. Std. IEC 68, 1987.

[7] W. H. Abbott, "The development and performance characteristics of mixed flowing gas test environment," IEEE Trans. Compon. Hybrids Manufact. Technol., vol. CHMT-1, no. 1, pp. 22-35, Mar. 1988.

[8] L. Lam, C. Maul, and J. W. McBride, "Temperature, humidity and pressure measurement on automotive connectors," IEEE Trans. Compon. Packag. Technol., vol. CAPT-29, no. 2, pp. 333-340, Jun. 2006.

[9] R. D. Malucci, D. L. Fowler, and F. R. Ruffino, "Field studies on the thermal environment for automotive applications," in Proc. 35th Annu. IICIT Connect. Interconn. Technol. Symp., 2002, [CD ROM].

[10] M. L. Topfer, Thick-Film Microelectronics-Fabrication, Design and Application. New York: Litton Educational Publishing, Inc, 1971.

[11] A. B. Bahaj, P. James, and J. McBride, "Photovoltaic connector behavior under accelerated fretting testing regimes," in Proc. 47h IEEE Holm Conf. Elect. Contacts, 2001, pp. 203-208.

[12] Standard for Automotive Electrical Connector Systems USCAR/ EWCAP, Tech. Rep. PF-1, 1994.

[13] J. K. Atkinson, R. P. Sion, and Z. Zhang, "Effects of aspect ratio on the temperature coefficient of resistance matching and low frequency noise levels in thick film strain sensors," Microelectron. Int., vol. 18, no. 1, pp. 40-42, 2001. 
[14] G. T. Flowers, F. Xie, M. J. Bozack, and R. D. Malucci, "Vibration thresholds for fretting corrosion in electrical connectors," IEEE Trans. Compon. Packag. Manufact. Technol. A, vol. 27, no. 1, pp. 65-71, Mar. 2004.

[15] G. T. Flowers, F. X. M. Bozack, X. Hai, B. I. Rickett, and R. D. Malucci, "A study of the physical characteristics of vibration-induced fretting corrosion," in Proc. 50th IEEE Holm Conf. Elect. Contacts, 22nd Int. Conf. Elect. Contacts, 2004, pp. 312-319.

Yu-Zhi (Liza) Lam received the B.Eng. and M.Eng. degrees in electrical and electronics engineering from Nanyang Technological University, Singapore, in 1997 and 2000, respectively, and the Ph.D. degree in research and development of the biomedical oxygen sensor from the Thick Film Unit, University of Southampton, Southampton, U.K., in 2003.

From 2003 to 2005, she was a Research Fellow at the Electromechanical Group, University of Southampton, working on sensors and conductive polymers for automotive applications. At the same time, she also lectured at the Faculty of Technology, Southampton Institute. Currently, she is carrying out research on single molecule detection as a Japan Society for the Promotion of Science (JSPS) Postdoctoral Research Fellow at Osaka University, Osaka, Japan. Her research interests include sensor design and development especially in the field of biomedical engineering and bioMEM/NEMs.

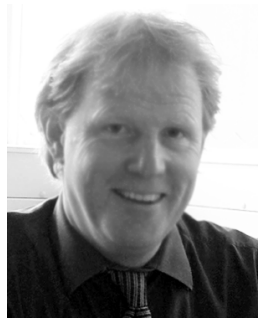

John W. McBride is Professor of electromechanical engineering in the School of Engineering Sciences, University of Southampton, Southampton, U.K. He is Chair of the Electro-Mechanical Research Group, and was previously Head of Research in the School (2001-2005). His main research interests include Electrical Contacts, Metrology and Instrumentation.

Dr. McBride received the IEEE Holm Scientific Achievement award in 2006. He is an Associate Editor of the IEEE TRANSACTIONS ON COMPONENTS AND PACKAGING TECHNOLOGIES and a member of the Organizing Committee, IEEE Holm Conference on Electrical Contacts.

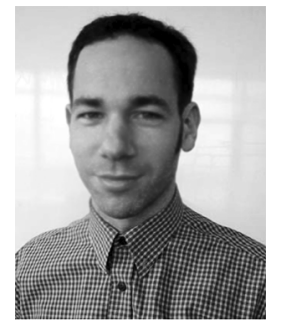

Christian Maul received the Dipl.-Ing. degree in mechanical engineering from the Technical University of Braunschweig, Braunschweig, Germany, in 1997 and the Ph.D. degree in fundamental and applied research in automotive connectors from the University of Southampton, Southampton, U.K., in 2001.

Currently, he is an Engineer and Chief Designer of the XYRIS System, TaiCaan Technologies, Southampton.

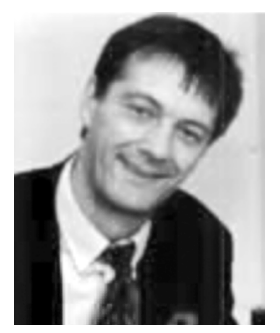

John K. Atkinson received the M.S. degree (with first class honors) in computer engineering from the University of Essex, Essex, U.K., in 1981 and the $\mathrm{Ph} . \mathrm{D}$. degree from the University of Southampton, Southampton, U.K., in 1999.

He began his career in 1970 as a Merchant Navy, Radio, and Electronics Officer. He was subsequently a Senior Engineer working on pattern recognition systems for speech, vision and hand-written computer input with Quest Automation Research, Ltd., prior to taking up the post of Lecturer in Electronics and Computer Science at the University of Southampton. He is currently a Reader in the School of Engineering Sciences and Editor of the Microelectronics International Journal. His research interests include thick-film technology, electronic instrumentation, and sensors. 